\title{
Increasing Trends in the Prevalence of Prior Cancer in Newly Diagnosed Lung, Stomach, Colorectal, Breast, and Uterine Cancer Patients: A Population- Based Study
}

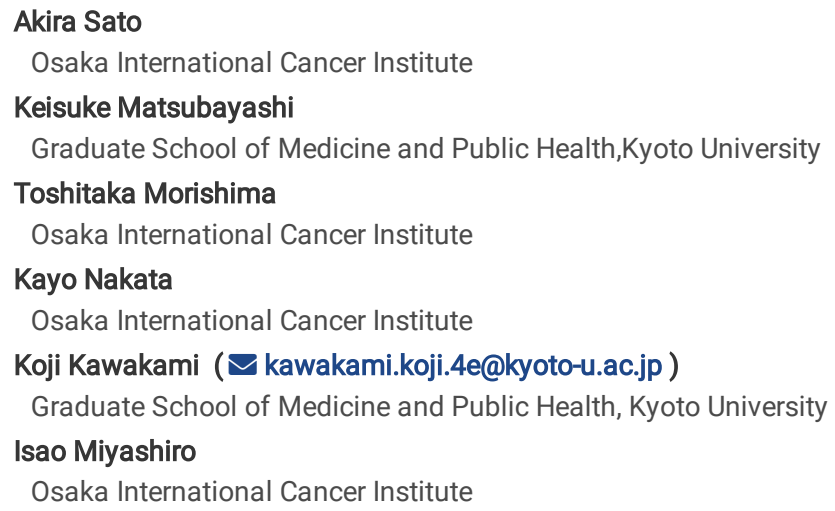

\section{Research article}

Keywords: Prior cancer, Cancer survivors, Cancer registry, Prevalence, Second cancer

Posted Date: July 13th, 2020

DOl: https://doi.org/10.21203/rs.3.rs-41046/v1

License: (c) (1) This work is licensed under a Creative Commons Attribution 4.0 International License. Read Full License

Version of Record: A version of this preprint was published on March 10th, 2021. See the published version at https://doi.org/10.1186/s12885-021-08011-3. 


\section{Abstract}

Background: Cancer survivors are frequently excluded from clinical research, resulting in their omission from the development of many cancer treatment strategies. Quantifying the prevalence of prior cancer in newly diagnosed cancer patients can inform research and clinical practice. This study aimed to describe the prevalence, characteristics, and trends of prior cancer in newly diagnosed cancer patients in Japan.

Methods: Using Osaka Cancer Registry data, we examined the prevalence, characteristics, and time trends of prior cancer in patients who received new diagnoses of lung, stomach, colorectal, female breast, or uterine cancer between 2004 and 2015. Site-specific prior cancers were examined for a maximum of 15 years before the new cancer was diagnosed. Time trends were evaluated using the Cochran-Armitage trend test.

Results: Among 275,895 newly diagnosed cancer patients, 21,757 (7.9\%) had prior cancer. The prevalence of prior cancer ranged from 3.3\% (breast cancer) to $11.1 \%$ (lung cancer). In both sexes, the age-adjusted prevalence of prior cancer had increased in recent years $(P$ values for trend $<0.001)$, especially in newly diagnosed lung cancer patients. The proportion of smoking-related prior cancers exceeded $50 \%$ in patients with newly diagnosed lung, stomach, colorectal, and breast cancer.

Conclusions: The prevalence of prior cancer in newly diagnosed cancer patients is relatively high, and has increased in recent years. Our findings suggest that a deeper understanding of the prevalence and characteristics of prior cancer in cancer patients is needed to promote more inclusive clinical research and support the expansion of treatment options.

\section{Introduction}

Cancer survivors are at risk of developing second primary cancers, and their numbers are increasing worldwide [1-5]. A study from the US Surveillance, Epidemiology, and End Results Program reported that almost 20\% of individuals with incident cancers between 2009 and 2013 had prior cancer [6]. The increasing incidence of second malignant cancers may be influenced by hereditary and familial risk, antecedent cancer therapy, lifestyle-related factors (e.g., tobacco and alcohol consumption), and environmental factors [7].

Cancer survivors require unique medical and psychosocial support with proactive assessments and follow-up care [4]. Several studies have reported that prior cancer did not adversely affect survival in lung and pancreatic cancer patients [8-11]. In contrast, another study noted that poorer survival was associated with some prior cancer types (e.g., colorectum, melanoma, and breast), but not others (e.g., esophagus, stomach, and lung) [12].

Despite the growing number of measures designed to support various aspects of cancer survivorship in patients, caregivers, and clinicians, further evidencebased resources are needed to improve the quality and effectiveness of cancer care. Identifying the occurrence and type of prior cancer in each newly diagnosed cancer patient can facilitate more accurate risk assessments in various clinical settings, including clinical cancer research. In addition, the frequent exclusion of cancer survivors from clinical research can lead to blind spots in the effectiveness and safety of treatment strategies for patients with metachronous cancers [13].

Insight into the prevalence and characteristics of prior cancer can inform research and clinical practice, but few studies have used population-based cancer registry data to examine these issues. In addition, most epidemiological evidence for the association between prior cancer and newly diagnosed cancer is derived from studies conducted in the US and Europe, with little evidence from Asian populations. The aim of this study was to provide globally comparable estimates of the prevalence, characteristics, and trends of prior cancer in newly diagnosed cancer patients using a long-term Japanese cancer registry database in order to aid further research and inform healthcare strategies.

\section{Methods}

\section{Data source and study design}

Data were obtained from the Osaka Cancer Registry (OCR), a population-based cancer registry founded in 1962 for the purpose of registering and monitoring all malignant tumors and benign intracranial tumors throughout Osaka prefecture (the third largest metropolitan area in Japan). The OCR covers a population of 8.8 million people, and allows the identification of prior cancers in individual patients [14].

Data on all cancer patients diagnosed between 1989 and 2015 were extracted for analysis. The various cancers were identified using the corresponding International Classification of Diseases, Tenth Revision (ICD-10) codes. The data also included each patient's age at diagnosis (hereinafter referred to as diagnostic age), sex, cancer detection method, cancer stage, treatment, month of diagnosis (diagnostic month), year of diagnosis (diagnostic year), inclusion in the registry through death certificate only, living status, and survival time.

We quantified the prevalence of prior cancer in patients who received new diagnoses of cancer of the following sites between 2004 and 2015 : lung, stomach, colorectum, female breast (hereinafter referred to as breast), and uterus. These sites were selected as they are the target sites for cancer screening programs in Japan, and are associated with high incidence [15]. We then examined the occurrence and types of prior cancers within 15 years before the diagnostic month and year of each newly diagnosed cancer.

\section{Definitions and study subjects}


Index cancers were defined as cancers that were newly diagnosed between 2004 and 2015 in patients who met the following criteria: 1) diagnostic age of 15-99 years, 2) pathologically diagnosed cancer for any of the target sites (lung, stomach, colorectum, breast, and uterus), and 3) survived for three months or more after diagnosis. In Osaka prefecture, the percentage of cases registered from death certificate only fell below $10 \%$ from 2004 onward [16]. Therefore, data from 2004 and later were used to identify the index cancer cases. Patients were excluded if they were registered in the OCR through death certificate only. Cases of multiple cancers are recorded in the OCR in accordance with the guidelines of the International Agency for Research on Cancer and the International Association of Cancer Registries [17]. However, multiple cancers of the same site in an individual patient were combined as the "most common prior cancer" to avoid including the incomplete integration of multiple prior cancers or metastatic cancers [5].

Prior cancers were defined as cancers diagnosed during the 15-year period before the index cancer diagnosis. If two or more prior cancers had the same diagnostic month and year in a patient, the sequence of these cancers was randomly determined using a previously described method [6].

We identified the index and prior cancer sites using the following ICD-10 codes [18]: all sites (C00-C96.x), mouth and pharynx (C00-C14.x), esophagus (C15.x), stomach (C16.x), colon (C18.x), rectum (C19.x-C20.x), liver (C22.x), gallbladder and bile duct (C23.x-C24.x), pancreas (C25.x), larynx (C32.x), lung (C33-C34.x), melanoma of skin (C43.x), other skin (C44.x), mesothelioma (C45.x), breast (C50.x), uterus (C53.x-C55.x), cervix uteri (C53.x), corpus uteri (C54.x), ovary (C56.x), prostate (C61.x), bladder (C67.x), renal and urinary tract (C64.x-C66.x, C68.x), brain and central nervous system (C70.x-C72.x), thyroid (C73.x), Hodgkin lymphoma (C81.x), non-Hodgkin lymphoma (C82.x-C86.x, C96.x), immunoproliferative diseases (C88.x), myeloma (C90.x), lymphoid leukemia (C91.x), acute myeloid leukemia (C92.0), myeloid leukemia (C92.x-C94.x), and unspecified leukemia (C95.x).

\section{Patient and index cancer characteristics}

For each patient, we analyzed age group $(15-39,40-44,45-49,50-54,55-59,60-64,65-69,70-74,75-79,80-84$, and 85-99 years), sex (male or female), method of cancer detection (screening and medical check-up, incidental detection during follow-up examination for another disease, and other or unknown; the last category generally involved cancer detection due to the occurrence of subjective symptoms)[19], cancer stage (localized, regional lymph nodes, regional extension, distant metastasis, and other or unknown), treatment (radiotherapy only, chemotherapy only, chemoradiotherapy, surgery only,

surgery plus chemotherapy or radiotherapy, and other or unknown), and diagnostic year (2004-2005, 2006-2007, 2008-2009, 2010-2011, 2012-2013, or 2014-2015). Missing values were included in the "unknown" category for each factor.

\section{Prior cancer characteristics}

For patients with prior cancer, we calculated the number of prior cancers before the index cancer, as well as the diagnostic time interval between the index cancer and most recent prior cancer. In addition, we examined the stage, treatment, and site of each prior cancer. The prior cancer site was identified for the most recent prior cancer. We categorized the following prior cancers as smoking-related cancers based on previous studies [20-24]: mouth, pharynx, larynx, lung, esophagus, stomach, liver, pancreas, kidney, urinary bladder, colorectum, uterine cervix, and acute myeloid leukemia.

\section{Statistical analysis}

The main outcome measure was the prevalence of prior cancer in the study subjects. In order to account for the varying age structures of the cancer patient population over time, we examined the trends in the age-adjusted prevalence (measured every two years) of prior cancer for each index cancer site according to sex. First, we calculated the age-specific prior cancer prevalence for each age group according to sex and cancer site. To obtain the expected number of prior cancer cases, we multiplied the age-specific prior cancer prevalence by the number of patients for each age group according to sex in our subjects between 2004 and 2015, which we had set as the reference cancer population. We then totaled the expected number of prior cancer cases from all age groups. Finally, to calculate the age-adjusted prevalence, we divided the total expected number of prior cancer cases by the reference cancer population. We described the time trends in prior cancer prevalence from 2004 to 2015 using the Cochran-Armitage trend test [25]. The distributions of the above sitespecific measurements were also examined according to sex.

Continuous variables were summarized as median values and interquartile ranges, and categorical variables were summarized as proportions. Proportions were compared using Pearson's chi-square test. The significance level was set at 5\% (two-sided). All analyses were performed using STATA version 14 (Stata corporation, College Station, TX, USA).

\section{Results}

\section{Prior cancer prevalence and patient characteristics}

Figure 1 shows the subject selection process. We identified 275,895 index cancer patients that met the inclusion and exclusion criteria. Among these, 21,757 (7.9\%) had prior cancer. As shown in Fig. 2, the age-adjusted prevalence of prior cancer had significantly increased over the study period for all index cancers in both male and female patients (all $P$ values $<0.001$ ). This prevalence was notably higher in lung cancer patients in both sexes.

The characteristics of the patients according to index cancer site are summarized in Table 1. The results for cervical cancer and corpus uterine cancer are described separately in Table A1 (Additional file). Among all patients, the prevalence of prior cancer was $11.1 \%$ in lung cancer patients, $9.5 \%$ in stomach cancer patients, $7.5 \%$ in colorectal cancer patients, $3.3 \%$ in breast cancer patients, and $4.5 \%$ in uterine cancer patients (cervix: $2.7 \%$, corpus: $6.7 \%$ ). Among 
older patients aged 65 years or older, the prevalence of prior cancer was $12.1 \%$ in lung cancer patients, $10.5 \%$ in stomach cancer patients, $8.4 \%$ in colorectal cancer patients, $5.2 \%$ in breast cancer patients, and $6.2 \%$ in uterine cancer patients (cervix: $5.4 \%$, corpus: $8.5 \%$ ). Patients whose index cancers were incidentally detected during follow-up examination for another disease had a higher prevalence of prior cancer than other cancer detection methods for all index cancer sites. The prevalence of prior cancer was also higher in patients whose index cancer was in the localized stage. With the exception of other or unknown treatments, surgery was the most common treatment for lung cancer $(16.9 \%)$, colorectal cancer $(8.2 \%)$, breast cancer (4.6\%), and uterine cancer (5.2\%). 
Table 1

Characteristics of newly diagnosed cancer patients according to index cancer site

\begin{tabular}{|c|c|c|c|c|c|c|c|c|c|c|c|c|c|c|c|}
\hline \multirow{3}{*}{$\begin{array}{l}\text { Index Cancer Site } \\
\mathrm{N}=275,895\end{array}$} & \multicolumn{3}{|l|}{ Lung } & \multicolumn{3}{|c|}{ Stomach } & \multicolumn{3}{|c|}{ Colorectum } & \multicolumn{3}{|l|}{ Breast } & \multicolumn{3}{|l|}{ Uterus } \\
\hline & \multirow{2}{*}{$\begin{array}{l}\text { Total } \\
\mathrm{N}\end{array}$} & \multicolumn{2}{|l|}{ Prior $^{a}$} & \multirow{2}{*}{$\begin{array}{l}\text { Total } \\
\mathrm{N}\end{array}$} & \multicolumn{2}{|l|}{ Prior $^{a}$} & \multirow{2}{*}{$\begin{array}{l}\text { Total } \\
\mathrm{N}\end{array}$} & \multicolumn{2}{|l|}{ Prior $^{a}$} & \multirow{2}{*}{$\begin{array}{l}\text { Total } \\
\mathrm{N}\end{array}$} & \multicolumn{2}{|l|}{ Prior $^{a}$} & \multirow{2}{*}{$\begin{array}{l}\text { Total } \\
\mathrm{N}\end{array}$} & \multicolumn{2}{|l|}{ Prior $^{\mathrm{a}}$} \\
\hline & & $\mathrm{N}$ & $\%$ & & $\mathrm{~N}$ & $\%$ & & $\mathrm{~N}$ & $\%$ & & $\mathrm{~N}$ & $\%$ & & $\mathrm{~N}$ & $\%$ \\
\hline Total & 56,930 & 6,309 & 11.1 & 78,092 & 7,382 & 9.5 & 77,032 & 5,757 & 7.5 & 47,860 & 1,588 & 3.3 & 15,981 & 721 & 4.5 \\
\hline \multicolumn{16}{|l|}{ Sex } \\
\hline Male & 39,040 & 4,628 & 11.9 & 54,479 & 5,800 & 10.6 & 44,535 & 3,841 & 8.6 & & & & & & \\
\hline Female & 17,890 & 1,681 & 9.4 & 23,613 & 1,582 & 6.7 & 32,497 & 1,916 & 5.9 & 47,860 & 1,588 & 3.3 & 15,981 & 721 & 4.5 \\
\hline \multicolumn{16}{|l|}{ Age, years } \\
\hline Median (IQR) & $\begin{array}{l}70 \\
(63- \\
76)\end{array}$ & \multicolumn{2}{|c|}{$73(67-78)$} & $\begin{array}{l}71 \\
(63- \\
77)\end{array}$ & \multicolumn{2}{|c|}{$74(68-79)$} & $\begin{array}{l}70 \\
(62- \\
77)\end{array}$ & \multicolumn{2}{|c|}{$73(67-79)$} & $\begin{array}{l}60 \\
(48- \\
69)\end{array}$ & \multicolumn{2}{|c|}{$69(61-76)$} & $\begin{array}{l}57 \\
(46- \\
67)\end{array}$ & \multicolumn{2}{|c|}{$63(53-74)$} \\
\hline $15-39$ & 455 & 15 & 3.3 & 864 & 8 & 0.9 & 961 & 10 & 1.0 & 3,034 & 23 & 0.8 & 2,162 & 27 & 1.2 \\
\hline $40-44$ & 551 & 20 & 3.6 & 919 & 17 & 1.8 & 1,191 & 29 & 2.4 & 4,556 & 35 & 0.8 & 1,455 & 30 & 2.1 \\
\hline $45-49$ & 1,032 & 39 & 3.8 & 1,572 & 39 & 2.5 & 1,974 & 47 & 2.4 & 5,737 & 61 & 1.1 & 1,577 & 66 & 4.2 \\
\hline $50-54$ & 1,965 & 98 & 5.0 & 2,954 & 107 & 3.6 & 3,508 & 103 & 2.9 & 4,885 & 91 & 1.9 & 1,784 & 97 & 5.4 \\
\hline 55-59 & 4,197 & 242 & 5.8 & 5,962 & 292 & 4.9 & 6,471 & 277 & 4.3 & 5,589 & 137 & 2.5 & 2,114 & 75 & 3.5 \\
\hline $60-64$ & 7,902 & 671 & 8.5 & 10,240 & 658 & 6.4 & 10,754 & 559 & 5.2 & 6,376 & 214 & 3.4 & 2,024 & 87 & 4.3 \\
\hline $65-69$ & 10,790 & 1,110 & 10.3 & 13,402 & 1,197 & 8.9 & 13,329 & 936 & 7.0 & 5,889 & 279 & 4.7 & 1,661 & 84 & 5.1 \\
\hline $70-74$ & 12,028 & 1,419 & 11.8 & 15,508 & 1,686 & 10.9 & 14,275 & 1,259 & 8.8 & 4,693 & 277 & 5.9 & 1,319 & 96 & 7.3 \\
\hline $75-79$ & 10,191 & 1,503 & 14.7 & 13,493 & 1,774 & 13.1 & 12,180 & 1,255 & 10.3 & 3,429 & 222 & 6.5 & 939 & 70 & 7.5 \\
\hline $80-84$ & 5,702 & 875 & 15.3 & 8,550 & 1,077 & 12.6 & 7,568 & 857 & 11.3 & 2,160 & 153 & 7.1 & 574 & 60 & 10.5 \\
\hline $85-99$ & 2,117 & 317 & 15.0 & 4,628 & 527 & 11.4 & 4,821 & 425 & 8.8 & 1,512 & 96 & 6.3 & 372 & 29 & 7.8 \\
\hline $\begin{array}{l}\text { Method of cancer } \\
\text { detection }\end{array}$ & & & & & & & & & & & & & & & \\
\hline $\begin{array}{l}\text { Screening and } \\
\text { medical check-up }\end{array}$ & 8,417 & 399 & 4.7 & 11,938 & 553 & 4.6 & 11,299 & 466 & 4.1 & 9,565 & 167 & 1.7 & 2,330 & 77 & 3.3 \\
\hline $\begin{array}{l}\text { Incidental } \\
\text { detection }^{\mathrm{b}}\end{array}$ & 19,365 & 4,222 & 21.8 & 20,721 & 4,003 & 19.3 & 15,244 & 2,728 & 17.9 & 3,938 & 666 & 16.9 & 1,919 & 224 & 11.7 \\
\hline Other or unknown & 29,148 & 1,688 & 5.8 & 45,433 & 2,826 & 6.2 & 50,489 & 2,563 & 5.1 & 34,357 & 755 & 2.2 & 11,732 & 420 & 3.6 \\
\hline Cancer stage & & & & & & & & & & & & & & & \\
\hline Localized & 17,540 & 2,986 & 17.0 & 43,352 & 5,027 & 11.6 & 35,289 & 3,152 & 8.9 & 28,498 & 1,087 & 3.8 & 8,960 & 444 & 5.0 \\
\hline $\begin{array}{l}\text { Regional lymph } \\
\text { nodes }\end{array}$ & 7,112 & 785 & 11.0 & 9,327 & 725 & 7.8 & 15,269 & 1,036 & 6.8 & 11,856 & 343 & 2.9 & 656 & 21 & 3.2 \\
\hline Regional extension & 8,188 & 782 & 9.6 & 8,477 & 509 & 6.0 & 9,034 & 581 & 6.4 & 2,179 & 44 & 2.0 & 4,134 & 158 & 3.8 \\
\hline Distant metastasis & 20,480 & 1,388 & 6.8 & 12,500 & 688 & 5.5 & 12,838 & 659 & 5.1 & 2,340 & 48 & 2.1 & 1,275 & 49 & 3.8 \\
\hline Other or unknown & 3,610 & 368 & 10.2 & 4,436 & 433 & 9.8 & 4,602 & 329 & 7.1 & 2,987 & 66 & 2.2 & 956 & 49 & 5.1 \\
\hline Treatment & & & & & & & & & & & & & & & \\
\hline Radiotherapy only & 3,116 & 471 & 15.1 & 48 & 14 & 29.2 & 93 & 6 & 6.5 & 214 & 3 & 1.4 & 899 & 44 & 4.9 \\
\hline Chemotherapy only & 15,195 & 1,076 & 7.1 & 7,455 & 543 & 7.3 & 1,974 & 142 & 7.2 & 1,984 & 38 & 1.9 & 405 & 16 & 4.0 \\
\hline Chemoradiotherapy & 7,394 & 515 & 7.0 & 166 & 38 & 22.9 & 184 & 13 & 7.1 & 185 & 4 & 2.2 & 1,200 & 35 & 2.9 \\
\hline Surgery only & 15,772 & 2,665 & 16.9 & 29,975 & 2,514 & 8.4 & 40,687 & 3,331 & 8.2 & 16,277 & 741 & 4.6 & 6,765 & 350 & 5.2 \\
\hline $\begin{array}{l}\text { Surgery plus } \\
\text { chemotherapy or } \\
\text { radiotherapy }\end{array}$ & 6,839 & 634 & 9.3 & 13,618 & 772 & 5.7 & 23,206 & 1,176 & 5.1 & 24,665 & 639 & 2.6 & 5,390 & 201 & 3.7 \\
\hline Other or unknown & 8,614 & 948 & 11.0 & 26,830 & 3,501 & 13.0 & 10,888 & 1,089 & 10.0 & 4,535 & 163 & 3.6 & 1,322 & 75 & 5.7 \\
\hline
\end{tabular}




\begin{tabular}{|c|c|c|c|c|c|c|c|c|c|c|c|c|c|c|c|}
\hline \multirow{2}{*}{$\begin{array}{l}\text { Index Cancer Site } \\
2004-2005\end{array}$} & \multicolumn{3}{|l|}{ Lung } & \multicolumn{3}{|c|}{ Stomach } & \multicolumn{3}{|c|}{ Colorectum } & \multicolumn{3}{|l|}{ Breast } & \multicolumn{3}{|l|}{ Uterus } \\
\hline & 7,288 & 538 & 7.4 & 9,969 & 635 & 6.4 & 9,151 & 498 & 5.4 & 5,650 & 143 & 2.5 & 1,992 & 83 & 4.2 \\
\hline $2006-2007$ & 8,407 & 803 & 9.6 & 11,542 & 892 & 7.7 & 11,295 & 743 & 6.6 & 6,913 & 206 & 3.0 & 2,193 & 84 & 3.8 \\
\hline 2008-2009 & 8,880 & 856 & 9.6 & 12,498 & 1,048 & 8.4 & 11,833 & 825 & 7.0 & 7,297 & 244 & 3.3 & 2,323 & 96 & 4.1 \\
\hline $2010-2011$ & 10,240 & 1,195 & 11.7 & 13,806 & 1,373 & 9.9 & 13,565 & 1,052 & 7.8 & 8,596 & 270 & 3.1 & 2,965 & 140 & 4.7 \\
\hline $2012-2013$ & 10,641 & 1,379 & 13.0 & 15,047 & 1,661 & 11.0 & 15,074 & 1,252 & 8.3 & 9,050 & 337 & 3.7 & 3,173 & 153 & 4.8 \\
\hline $2014-2015$ & 11,474 & 1,538 & 13.4 & 15,230 & 1,773 & 11.6 & 16,114 & 1,387 & 8.6 & 10,354 & 388 & 3.7 & 3,335 & 165 & 4.9 \\
\hline \multicolumn{16}{|c|}{ 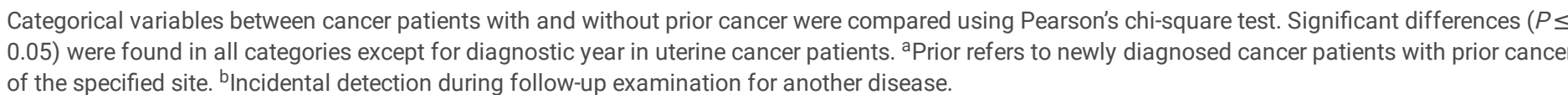 } \\
\hline
\end{tabular}

\section{Prior cancer characteristics}

The characteristics of male and female patients with prior cancer are shown in Table 2 and Table 3, respectively. Approximately $90 \%$ of these patients had only one prior cancer regardless of sex. The proportions of male patients with two prior cancers were $10.4 \%$ for lung cancer, $8.7 \%$ for stomach cancer, and $8.9 \%$ for colorectal cancer. In female patients, these proportions were $7.2 \%$ for lung cancer, $5.6 \%$ for stomach cancer, $6.1 \%$ for colorectal cancer, $5.0 \%$ for breast cancer, and $6.4 \%$ for uterine cancer (cervix: $7.3 \%$, corpus: $5.4 \%$ ). The cumulative proportions of the most recent prior cancers diagnosed within 5 years before the index cancer diagnosis were $69.4 \%$ (male) and $65.0 \%$ (female) for lung cancer, $75.0 \%$ (male) and $67.4 \%$ (female) for stomach cancer, $75.5 \%$ (male) and 65.3\% (female) for colorectal cancer, 65.2\% (female) for breast cancer, and $57.7 \%$ (female) for uterine cancer (cervix: $69.0 \%$, corpus: $54.7 \%$ ). The most common and least common prior cancer stages were localized and distant metastasis, respectively. Surgery only was the most common treatment for prior cancer across all index cancer sites in both sexes. 
Table 2

Characteristics of newly diagnosed male cancer patients with prior cancer

\begin{tabular}{|c|c|c|c|c|c|c|c|c|}
\hline \multirow[t]{2}{*}{ Index Cancer Site } & \multicolumn{2}{|l|}{ Lung } & \multicolumn{2}{|c|}{ Stomach } & \multicolumn{2}{|c|}{ Colorectum } & \multicolumn{2}{|l|}{ Total } \\
\hline & $\mathrm{N}$ & $\%$ & $\mathrm{~N}$ & $\%$ & $\mathrm{~N}$ & $\%$ & $\mathrm{~N}$ & $\%$ \\
\hline Total & 4,628 & 100 & 5,800 & 100 & 3,841 & 100 & 14,269 & 100 \\
\hline \multicolumn{9}{|l|}{ Number of prior cancers before the index cancer } \\
\hline 1 & 4,100 & 88.6 & 5,256 & 90.6 & 3,457 & 90.0 & 12,813 & 89.8 \\
\hline 2 & 481 & 10.4 & 507 & 8.7 & 343 & 8.9 & 1,331 & 9.3 \\
\hline 3 & 44 & 1.0 & 35 & 0.6 & 39 & 1.0 & 118 & 0.8 \\
\hline 4 & 2 & 0.0 & 2 & 0.0 & 1 & 0.0 & 5 & 0.0 \\
\hline 5 & 1 & 0.0 & 0 & 0.0 & 1 & 0.0 & 2 & 0.0 \\
\hline \multicolumn{9}{|l|}{ Diagnostic time interval ${ }^{\mathrm{a}}$} \\
\hline$<3$ months & 741 & 16.0 & 1,687 & 29.1 & 1,240 & 32.3 & 3,668 & 25.7 \\
\hline 3 months -1 year & 555 & 12.0 & 656 & 11.3 & 428 & 11.1 & 1,639 & 11.5 \\
\hline $1-5$ years & 1,916 & 41.4 & 2,006 & 34.6 & 1,232 & 32.1 & 5,154 & 36.1 \\
\hline $5-10$ years & 988 & 21.3 & 1,017 & 17.5 & 641 & 16.7 & 2,646 & 18.5 \\
\hline $10-15$ years & 428 & 9.2 & 434 & 7.5 & 300 & 7.8 & 1,162 & 8.1 \\
\hline \multicolumn{9}{|l|}{ Stage of prior cancer ${ }^{b}$} \\
\hline Localized & 2,941 & 63.5 & 3,320 & 57.2 & 2,308 & 60.1 & 8,569 & 60.1 \\
\hline Regional lymph nodes & 455 & 9.8 & 650 & 11.2 & 350 & 9.1 & 1,455 & 10.2 \\
\hline Regional extension & 528 & 11.4 & 797 & 13.7 & 501 & 13.0 & 1,826 & 12.8 \\
\hline Distant metastasis & 229 & 4.9 & 453 & 7.8 & 325 & 8.5 & 1,007 & 7.1 \\
\hline Other or unknown & 475 & 10.3 & 580 & 10.0 & 357 & 9.3 & 1,412 & 9.9 \\
\hline \multicolumn{9}{|l|}{ Treatment of prior cancer ${ }^{b}$} \\
\hline Radiotherapy only & 185 & 4.0 & 265 & 4.6 & 152 & 4.0 & 602 & 4.2 \\
\hline Chemotherapy only & 252 & 5.4 & 438 & 7.6 & 310 & 8.1 & 1,000 & 7.0 \\
\hline Chemoradiotherapy & 148 & 3.2 & 296 & 5.1 & 141 & 3.7 & 585 & 4.1 \\
\hline Surgery only & 1,986 & 42.9 & 2,246 & 38.7 & 1,468 & 38.2 & 5,700 & 39.9 \\
\hline Surgery plus chemotherapy or radiotherapy & 631 & 13.6 & 893 & 15.4 & 535 & 13.9 & 2,059 & 14.4 \\
\hline Other or unknown & 1,426 & 30.8 & 1,662 & 28.7 & 1,235 & 32.2 & 4,323 & 30.3 \\
\hline \multicolumn{9}{|l|}{ Site of prior cancer ${ }^{b}$} \\
\hline Mouth and pharynx & 209 & 4.5 & 254 & 4.4 & 137 & 3.6 & 600 & 4.2 \\
\hline Esophagus & 236 & 5.1 & 646 & 11.1 & 172 & 4.5 & 1,054 & 7.4 \\
\hline Stomach & 1,290 & 27.9 & - & - & 1,302 & 33.9 & 2,592 & 18.2 \\
\hline Colon & 543 & 11.7 & 970 & 16.7 & - & - & 1,513 & 10.6 \\
\hline Rectum & 342 & 7.4 & 602 & 10.4 & - & - & 944 & 6.6 \\
\hline Liver & 234 & 5.1 & 570 & 9.8 & 278 & 7.2 & 1,082 & 7.6 \\
\hline Gallbladder and bile duct & 40 & 0.9 & 75 & 1.3 & 56 & 1.5 & 171 & 1.2 \\
\hline Pancreas & 45 & 1.0 & 69 & 1.2 & 35 & 0.9 & 149 & 1.0 \\
\hline Larynx & 172 & 3.7 & 198 & 3.4 & 90 & 2.3 & 460 & 3.2 \\
\hline
\end{tabular}

Values are expressed as the number of patients and column percentage.

anterval between the diagnostic dates of the most recent prior cancer and index cancer.

bMost recently diagnosed prior cancer. 


\begin{tabular}{|c|c|c|c|c|c|c|c|c|}
\hline \multirow{2}{*}{$\begin{array}{l}\text { Index Cancer Site } \\
\text { Lung }\end{array}$} & \multicolumn{2}{|c|}{ Lung } & \multicolumn{2}{|c|}{ Stomach } & \multicolumn{2}{|c|}{ Colorectum } & \multicolumn{2}{|l|}{ Total } \\
\hline & - & - & 591 & 10.2 & 386 & 10.0 & 977 & 6.8 \\
\hline Melanoma of skin & 4 & 0.1 & 7 & 0.1 & 4 & 0.1 & 15 & 0.1 \\
\hline Other skin & 73 & 1.6 & 67 & 1.2 & 66 & 1.7 & 206 & 1.4 \\
\hline Mesothelioma & 4 & 0.1 & 7 & 0.1 & 9 & 0.2 & 20 & 0.1 \\
\hline Prostate & 687 & 14.8 & 924 & 15.9 & 646 & 16.8 & 2,257 & 15.8 \\
\hline Bladder & 265 & 5.7 & 281 & 4.8 & 213 & 5.5 & 759 & 5.3 \\
\hline Renal and urinary tract & 164 & 3.5 & 185 & 3.2 & 172 & 4.5 & 521 & 3.7 \\
\hline Brain and central nervous system & 5 & 0.1 & 8 & 0.1 & 7 & 0.2 & 20 & 0.1 \\
\hline Thyroid & 38 & 0.8 & 42 & 0.7 & 38 & 1.0 & 118 & 0.8 \\
\hline Hodgkin lymphoma & 12 & 0.3 & 4 & 0.1 & 8 & 0.2 & 24 & 0.2 \\
\hline Non-Hodgkin lymphoma & 118 & 2.5 & 142 & 2.4 & 97 & 2.5 & 357 & 2.5 \\
\hline Immunoproliferative diseases & 1 & 0.0 & 1 & 0.0 & 0 & 0.0 & 2 & 0.0 \\
\hline Myeloma & 18 & 0.4 & 19 & 0.3 & 17 & 0.4 & 54 & 0.4 \\
\hline Lymphoid leukemia & 13 & 0.3 & 11 & 0.2 & 8 & 0.2 & 32 & 0.2 \\
\hline Myeloid leukemia & 13 & 0.3 & 17 & 0.3 & 14 & 0.4 & 44 & 0.3 \\
\hline Leukemia unspecified & 0 & 0.0 & 0 & 0.0 & 1 & 0.0 & 1 & 0.0 \\
\hline Others & 102 & 2.2 & 110 & 1.9 & 85 & 2.2 & 297 & 2.1 \\
\hline \multicolumn{9}{|c|}{ Values are expressed as the number of patients and column percentage. } \\
\hline \multicolumn{9}{|c|}{${ }^{a}$ Interval between the diagnostic dates of the most recent prior cancer and index cancer. } \\
\hline
\end{tabular}


Table 3

Characteristics of newly diagnosed female cancer patients with prior cancer

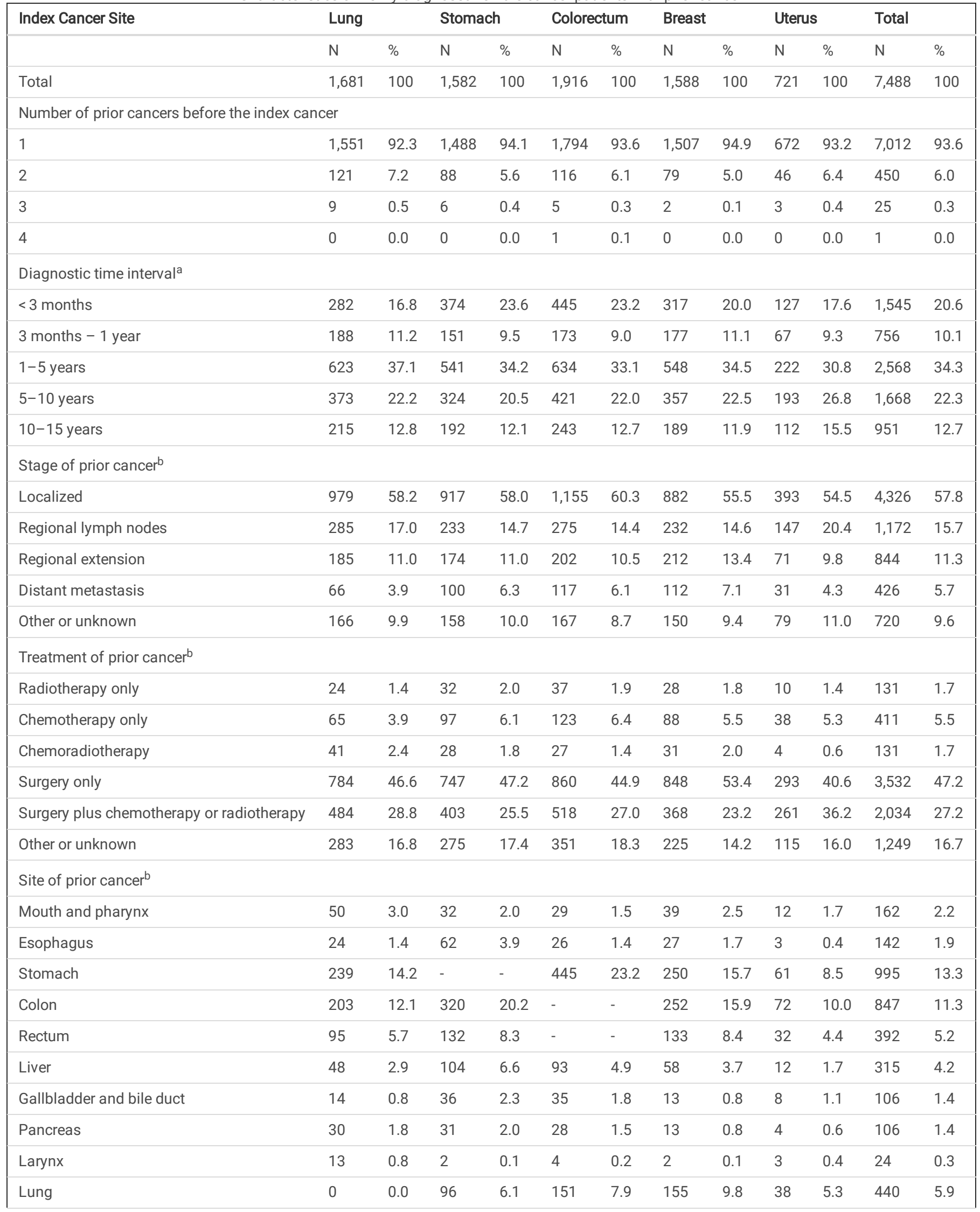

Values are expressed as the number of patients and column percentage.

a Interval between the diagnostic dates of the most recent prior cancer and index cancer.

${ }^{\mathrm{b}}$ Most recently diagnosed prior cancer. 


\begin{tabular}{|c|c|c|c|c|c|c|c|c|c|c|c|c|}
\hline $\begin{array}{l}\text { Index Cancer Site } \\
\text { Melanoma of skin }\end{array}$ & \multicolumn{2}{|c|}{ Lung } & \multicolumn{2}{|c|}{ Stomach } & \multicolumn{2}{|c|}{ Colorectum } & \multicolumn{2}{|c|}{ Breast } & \multicolumn{2}{|c|}{ Uterus } & \multicolumn{2}{|l|}{ Total } \\
\hline Other skin & 27 & 1.6 & 42 & 2.7 & 39 & 2.0 & 30 & 1.9 & 15 & 2.1 & 153 & 2.0 \\
\hline Mesothelioma & 1 & 0.1 & 0 & 0.0 & 0 & 0.0 & 0 & 0.0 & 0 & 0.0 & 1 & 0.0 \\
\hline Breast & 485 & 28.9 & 378 & 23.9 & 528 & 27.6 & - & - & 311 & 43.1 & 1,702 & 22.7 \\
\hline Corpus uteri & 66 & 3.9 & 45 & 2.8 & 108 & 5.6 & 132 & 8.3 & - & - & 351 & 4.7 \\
\hline Uterus & 6 & 0.4 & 3 & 0.2 & 5 & 0.3 & 7 & 0.4 & - & - & 21 & 0.3 \\
\hline Ovary & 46 & 2.7 & 25 & 1.6 & 56 & 2.9 & 60 & 3.8 & 49 & 6.8 & 236 & 3.2 \\
\hline Bladder & 27 & 1.6 & 27 & 1.7 & 38 & 2.0 & 23 & 1.4 & 14 & 1.9 & 129 & 1.7 \\
\hline Hodgkin lymphoma & 4 & 0.2 & 1 & 0.1 & 3 & 0.2 & 1 & 0.1 & 1 & 0.1 & 10 & 0.1 \\
\hline Non-Hodgkin lymphoma & 38 & 2.3 & 56 & 3.5 & 50 & 2.6 & 48 & 3.0 & 23 & 3.2 & 215 & 2.9 \\
\hline Immunoproliferative diseases & 0 & 0.0 & 0 & 0.0 & 1 & 0.1 & 1 & 0.1 & 0 & 0.0 & 2 & 0.0 \\
\hline Myeloma & 2 & 0.1 & 9 & 0.6 & 12 & 0.6 & 7 & 0.4 & 4 & 0.6 & 34 & 0.5 \\
\hline Lymphoid leukemia & 4 & 0.2 & 2 & 0.1 & 2 & 0.1 & 1 & 0.1 & 2 & 0.3 & 11 & 0.1 \\
\hline Myeloid leukemia & 4 & 0.2 & 7 & 0.4 & 8 & 0.4 & 9 & 0.6 & 3 & 0.4 & 31 & 0.4 \\
\hline Others & 41 & 2.4 & 38 & 2.4 & 52 & 2.7 & 41 & 2.6 & 13 & 1.8 & 185 & 2.5 \\
\hline
\end{tabular}

The most common sites of the most recent prior cancers were analyzed according to index cancer site in male patients (Table 2) and female patients (Table 3). The results for cervical cancer and corpus uterine cancer are described separately in Table A2 (Additional file). In male patients, smoking-related cancers accounted for approximately $70 \%$ of prior cancer. In female patients, smoking-related prior cancers were more common in index breast cancer patients than patients with other index cancers. Patients with cervical cancer had a significantly higher proportion of smoking-related cancers than those with corpus uterine cancer in Figure A1 (Additional file). The proportions of smoking-related prior cancers in male patients were significantly higher than in female patients for index lung, stomach, and colorectal cancer (Fig. 3).

\section{Discussion}

In this analysis of population-based cancer registry data from a major metropolitan area in Japan, we ascertained the prevalence, characteristics, and trends of prior cancer in patients newly diagnosed with one of five major cancer types. Even after accounting for the changes in age structure, the prevalence of prior cancer was found to have increased over time for all index cancer sites. These trends may be attributable to earlier detection (increase in localized cancer rates: $35.2 \%$ in $2004,48.4 \%$ in 2015), longer survival (increase in relative survival: $42.3 \%$ in 2004, 56.2\% in 2010), and expanded cancer registry coverage (decrease in the percentages of cases with death certificate notification or death certificate only) in more recently diagnosed cancer patients [15, 26 , 27].

Among our subjects, patients with newly diagnosed lung cancer had the highest prevalence of prior cancer among the assessed index cancers. These differences in the prevalences of prior cancer may be indicative of underlying or shared risk factors (e.g., lifestyle habits such as smoking), and require further investigation.

Our analysis showed that the prevalence of prior cancer increased with age for all index cancers, with adolescents and young adults (aged 15-39 years) having a lower prevalence than older patients. However, our estimated prevalences of prior cancer in patients aged 65 years or older were lower than those reported in a previous study conducted in the US (lung: $18.7 \%$, stomach: $17.8 \%$, colorectum: $15.3 \%$, breast: $7.4 \%$, cervix: $13.6 \%$, and corpus: $13.6 \%$ ) [6]. This disparity may be influenced by an inherent difference in the age-standardized cancer incidence rates for all sites between the US (393.2 per 100,000 population) and Japan (285.9 per 100,000 population) [28]. In addition to variations in prior cancer prevalence, this may also be indicative of differences in genetic, lifestyle-related, and/or environmental risk factors. Differences in the prevalence of prior cancers among previous studies may also be explained in part by our non-inclusion of patients with carcinoma in situ, as this condition is generally curable and would not unduly affect survival. In addition, we did not use the recorded sequence numbers that indicate the order of cancer in individual cases, which may also have resulted in a lower apparent prevalence of 
prior cancer. We had decided to exclude prior cancers at the same site as the index cancer to avoid potential double counting because we would be unable to determine if the index cancer was metastatic or primary.

The prevalence of prior cancer was found to be higher in index cancer patients with localized tumors, and prior cancers were generally diagnosed in the early localized stage across all index cancers. A possible explanation for the former observation is that patients with prior cancer would undergo regular follow-up examinations, which would support the prompt incidental detection of new tumors in the early stages. This may also contribute to the high prevalence of prior cancer for patients whose index cancers were incidentally detected during examinations for another disease. For the latter observation, we posit that patients with cancers diagnosed in the earlier stages would receive prompt treatment and have longer survival, thereby increasing the opportunities for other cancers to develop. Our results also showed that surgical treatment was often selected for prior cancer, which may be due to the high proportion of earlystage cancers.

In the present study, the prevalence of prior cancers in male patients was higher than in female patients. In particular, the proportion of male patients with two or more prior cancers was higher than female patients for new cases of lung cancer, stomach cancer, and colorectal cancer. The cumulative proportions of the most recent prior cancers diagnosed within 5 years before the index cancer diagnosis were higher in male patients (Table 2 and Table 3 ). These observations may be influenced by the higher incidence of cancers in men, lifestyle differences, and other sex-based differences [29].

While our data did not include information on tobacco consumption, smoking-related prior cancers were found to be less common in female patients newly diagnosed with lung, stomach, and colorectal cancer than their male counterparts. The proportions of smoking-related prior cancers were $73.1 \%$ in male patients and $53.0 \%$ in female patients among the general population of cancer patients $(P<0.001)$. This may indicate a biological difference in susceptibility to smoking-related cancer between the sexes [30,31]. In addition, the proportion of smokers may be higher among male patients, which could have contributed to their higher prevalence of smoking-related prior cancers. Furthermore, female patients with index breast cancer had a higher proportion of smoking-related prior cancers than those with other index cancers. Although several studies have reported that smoking is associated with an increased risk of breast cancer [32-34], the evidence remains inconclusive and further research is needed to understand these findings. Patients with cervical cancer had a significantly higher rate of smoking-related cancers than those with corpus uterine cancer, likely because cervical cancer is a smoking-related cancer and has a common cause, such as smoking.

Our results also showed that patients with index breast cancer had a higher prevalence of prior corpus uterine cancer (8.3\%) relative to the general cancer population (3.7\%) in the OCR [15]. Similarly, patients with index corpus uterine cancer had a higher prevalence of prior breast cancer (46.6\%) relative to the general cancer population (20.7\%) in the OCR [15]. In addition, there was a slightly higher prevalence of prior ovary cancer in patients with index breast cancer (3.8\%) than the general cancer population (2.4\%) [15]. This may be indicative of hereditary cancers (such as hereditary breast and ovarian cancer syndrome, Lynch syndrome, and Li-Fraumeni syndrome) or the effects of previous treatments for prior cancers [35, 36].

Cases with prior cancer are frequently excluded from clinical research. However, the relatively high prevalence of prior cancer in newly diagnosed cancer patients suggests that their exclusion would have a substantial effect on research outcomes. Approximately $80 \%$ of previous clinical trials for lung cancer patients excluded those with prior cancer, and most trials employ a 5-year exclusion window [13,37]. Patients with prior cancer are also sometimes excluded from observational studies due to concerns that they may affect outcome measurements [38, 39]. Our present study found that approximately $70 \%$ of lung, stomach, and colorectal cancer patients with prior cancer had a diagnostic interval of 5 years or less between the prior and index cancers. In addition, the most frequent diagnostic interval was 1-5 years for all index cancer sites. Even after excluding cancer patients with a diagnostic interval of 3 months or less, individuals who had a diagnostic interval of 5 years or less still accounted for more than $60 \%$ of patients with prior cancer. Accordingly, a considerable proportion of patients with prior cancer would not be eligible to participate in trials with a 5-year exclusion window. The impact of prior cancer on survival should be examined with scientific evidence, and cancer survivors should not be excluded from studies as a matter of course [40]. Quantifying the prevalence of prior cancer in newly diagnosed cancer patients can aid our understanding of these patients and support the formulation of comprehensive treatment strategies. For example, medical institutions, government agencies, and insurers may be able to design more efficient strategies to allocate health resources and develop treatment plans that account for cancer survivors [41-44].

This study has the following limitations. First, we created sequence numbers for multiple cancers in the OCR with the assumption that patients did not move outside of the cancer registry catchment area (i.e., Osaka prefecture). However, the number of prior cancers may be underestimated if there was substantial movement out of this area. Nevertheless, if the actual prevalence of prior cancer is actually higher, this would further reinforce our conclusions. Second, there were limitations to the types of information available in the registry, which prevented a more detailed analysis of patient background factors such as tobacco use, alcohol use, and obesity.

Our study has several strengths. Using a historic, large-scale cancer registry database, we were able to identify and characterize prior cancers in newly diagnosed cancer patients residing in a major metropolitan area in Japan. To the best of our knowledge, this is the first study to reveal recent trends in the age-adjusted prevalence of prior cancers stratified by sex.

\section{Conclusions}

This study provided globally comparable estimates of the prevalence and characteristics of prior cancer in newly diagnosed cancer patients using a longterm population-based cancer registry. The prevalence of prior cancer increased in recent years, and approximately $70 \%$ of prior cancers in male patients were potentially smoking-related. In light of the increasing number of cancer survivors worldwide, our findings suggest that a deeper understanding of the prevalence and characteristics of prior cancer in cancer patients is needed to promote more inclusive clinical research and support the expansion of treatment options. 


\author{
Abbreviations \\ OCR: Osaka Cancer Registry \\ ICD-10: International Classification of Diseases, Tenth Revision
}

\title{
Declarations
}

\section{Ethics approval and consent to participate:}

This study was approved by the Research Ethics Committee of Osaka International Cancer Institute (Approval No. 18-0020; December 6, 2018) and the Kyoto University Graduate School of Medicine Ethics Committee (Approval No. R1808; December 18, 2018). The ethics committees waived the need for informed consent from the OCR-registered patients as the data were anonymized before being received by the authors. The study was performed in accordance with the ethical standards outlined in the Declaration of Helsinki.

\section{Consent for publication:}

Not applicable

\section{Availability of data and materials:}

The datasets used and/or analyzed during the current study are available from the corresponding author on reasonable request.

\section{Competing interests:}

K. Kawakami has received research funds from Stella Pharma Corporation. The sponsor had no control over the interpretation, writing, or publication of this work. No potential conflicts of interest were disclosed by the other authors.

\section{Funding:}

This study was supported by grants from the Osaka Health and Medical Foundation, the Osaka Foundation for the Prevention of Cancer and Lifestyle-related Diseases, and the Ministry of Health, Labour and Welfare, Japan (H30-Gantaisaku-Ippan-009). The funders had no role in the study design, data collection and analysis, decision to publish, or preparation of the manuscript.

\section{Authors' contributions:}

Conceptualization, data curation and methodology: A. Sato

Investigation and writing, review, and/or revision of the manuscript: A. Sato, K. Matsubayashi, T. Morishima, K. Nakata, K. Kawakami, I. Miyashiro

Supervision: K. Kawakami, I. Miyashiro

\section{Acknowledgements:}

We are grateful to Dr. Takahiro Tabuchi and Dr. Akira Oshima of the Cancer Control Center, Osaka International Cancer Institute, for their technical assistance.

\section{References}

1. Allemani C, Matsuda T, Di Carlo V, Harewood R, Matz M, Nikšić M, Bonaventure A, Valkov M, Johnson CJ, Estève J et al: Global surveillance of trends in cancer survival 2000-14 (CONCORD-3): analysis of individual records for 37513025 patients diagnosed with one of 18 cancers from 322 populationbased registries in 71 countries. The Lancet 2018, 391(10125):1023-1075.

2. Bray F, Ferlay J, Soerjomataram I, Siegel RL, Torre LA, Jemal A: Global cancer statistics 2018: GLOBOCAN estimates of incidence and mortality worldwide for 36 cancers in 185 countries. CA Cancer J Clin 2018, 68(6):394-424.

3. Miller KD, Siegel RL, Lin CC, Mariotto AB, Kramer JL, Rowland JH, Stein KD, Alteri R, Jemal A: Cancer treatment and survivorship statistics, 2016. CA Cancer J Clin 2016, 66(4):271-289.

4. Miller KD, Nogueira L, Mariotto AB, Rowland JH, Yabroff KR, Alfano CM, Jemal A, Kramer JL, Siegel RL: Cancer treatment and survivorship statistics, 2019. CA Cancer J Clin 2019.

5. Tabuchi T, Ito Y, loka A, Miyashiro I, Tsukuma H: Incidence of metachronous second primary cancers in Osaka, Japan: update of analyses using population-based cancer registry data. Cancer Sci 2012, 103(6):1111-1120. 
6. Murphy CC, Gerber DE, Pruitt SL: Prevalence of Prior Cancer Among Persons Newly Diagnosed With Cancer: An Initial Report From the Surveillance, Epidemiology, and End Results Program. JAMA Oncol 2018, 4(6):832-836.

7. Wood ME, Vogel V, Ng A, Foxhall L, Goodwin P, Travis LB: Second malignant neoplasms: assessment and strategies for risk reduction. J Clin Onco/ 2012, 30(30):3734-3745.

8. Laccetti AL, Pruitt SL, Xuan L, Halm EA, Gerber DE: Effect of prior cancer on outcomes in advanced lung cancer: implications for clinical trial eligibility and accrual. J Natl Cancer Inst 2015, 107(4).

9. Pruitt SL, Laccetti AL, Xuan L, Halm EA, Gerber DE: Revisiting a longstanding clinical trial exclusion criterion: impact of prior cancer in early-stage lung cancer. Br J Cancer 2017, 116(6):717-725.

10. Laccetti AL, Pruitt SL, Xuan L, Halm EA, Gerber DE: Prior cancer does not adversely affect survival in locally advanced lung cancer: A national SEERmedicare analysis. Lung Cancer 2016, 98:106-113.

11. He C, Zhang Y, Cai Z, Lin X: Effect of prior cancer on survival outcomes for patients with pancreatic adenocarcinoma: a propensity score analysis. $B M C$ Cancer 2019, 19(1):509.

12. Zhou H, Huang Y, Qiu Z, Zhao H, Fang W, Yang Y, Zhao Y, Hou X, Ma Y, Hong S et al: Impact of prior cancer history on the overall survival of patients newly diagnosed with cancer: A pan-cancer analysis of the SEER database. Int J Cancer 2018.

13. Gerber DE, Pruitt SL, Halm EA: Should criteria for inclusion in cancer clinical trials be expanded? J Comp Eff Res 2015, 4(4):289-291.

14. Tsukuma H, Fujimoto I, Hanai A, Hiyama T, Kitagawa T, Kinoshita N: Incidence of second primary cancers in Osaka residents, Japan, with special reference to cumulative and relative risks. Japanese journal of cancer research : Gann 1994, 85(4):339-345.

15. Osaka Prefectural Department of Public Health and Welfare, Osaka Medical Association, Osaka International Cancer Institute: Annual Report of Osaka

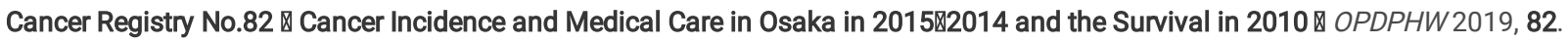

16. Parkin DM, Chen VW, Ferlay J, Galceran J, Storm HH, SL W: Comparability and Quality Control in Cancer Registration, IARC Technical Report No. 19. IARC, Lyon 1994.

17. Group RW: International rules for multiple primary cancers (ICD-O third edition). European journal of cancer prevention : the official journal of the European Cancer Prevention Organisation (ECP) 2005, 14(4):307-308.

18. World Health Organization: International Statistical Classification of Diseases and Health Related Problems (The) ICD-10 Second Edition. World Health Organization 2004.

19. Department of Public Health and Medical Affairs Osaka Prefectural Government, Cancer Control Center Osaka International Cancer Institute: Annual Report of Osaka Cancer Registry vol. 84: Cancer Incidence and Treatment in 2016 and Cancer Survival in 2011 in Osaka. Osaka Prefectural Government 2020,84

20. Aguilo R, Macia F, Porta M, Casamitjana M, Minguella J, Novoa AM: Multiple independent primary cancers do not adversely affect survival of the lung cancer patient. Eur J Cardiothorac Surg 2008, 34(5):1075-1080.

21. Warren GW, Alberg AJ, Kraft AS, Cummings KM: The 2014 Surgeon General's report: "The health consequences of smoking-50 years of progress": a paradigm shift in cancer care. Cancer 2014, 120(13):1914-1916.

22. Shiels MS, Gibson T, Sampson J, Albanes D, Andreotti G, Beane Freeman L, Berrington de Gonzalez A, Caporaso N, Curtis RE, Elena J et al: Cigarette smoking prior to first cancer and risk of second smoking-associated cancers among survivors of bladder, kidney, head and neck, and stage I lung cancers. J Clin Oncol 2014, 32(35):3989-3995.

23. Fircanis S, Merriam P, Khan N, Castillo JJ: The relation between cigarette smoking and risk of acute myeloid leukemia: an updated meta-analysis of epidemiological studies. Am J Hematol 2014, 89(8):E125-132.

24. Ugai T, Matsuo K, Oze I, Ito H, Wakai K, Wada K, Nagata C, Nakayama T, Liu R, Kitamura Y et al: Smoking and subsequent risk of acute myeloid leukaemia: A pooled analysis of 9 cohort studies in Japan. Hematol Oncol 2018, 36(1):262-268.

25. Armitage P: Tests for Linear Trends in Proportions and Frequencies. Biometrics 1955, 11(3):375-386.

26. Osaka Prefectural Department of Public Health and Welfare, Osaka Medical Association, Osaka Medical Center for Cancer and Cardiovascular Disease: Annual Report of Osaka Cancer Registry No.80 \ Cancer Incidence and Medical Care in Osaka in 2012ख2011 and the Survival in 2009 \ OPDPHW2016, 80.

27. Osaka Prefectural Department of Public Health and Welfare, Osaka Medical Association, Osaka International Cancer Institute: Annual Report of Osaka Cancer Registry No.81 \ Cancer Incidence and Medical Care in Osaka in 2013 《 OPDPHW 2017, 82.

28. Bray F, Colombet M, Mery L, Piñeros M, Znaor A, Zanetti R, Ferlay J, editors: Cancer Incidence in Five Continents, Vol. XI (electronic version). International Agency for Research on Cancer 2017(166).

29. Shin JY, Jung HJ, Moon A: Molecular Markers in Sex Differences in Cancer. Toxicological research 2019, 35(4):331-341.

30. Yu Y, Liu H, Zheng S, Ding Z, Chen Z, Jin W, Wang L, Wang Z, Fei Y, Zhang S et al: Gender susceptibility for cigarette smoking-attributable lung cancer: a systematic review and meta-analysis. Lung Cancer 2014, 85(3):351-360.

31. Li WY, Han Y, Xu HM, Wang ZN, Xu YY, Song YX, Xu H, Yin SC, Liu XY, Miao ZF: Smoking status and subsequent gastric cancer risk in men compared with women: a meta-analysis of prospective observational studies. BMC Cancer 2019, 19(1):377.

32. Jones ME, Schoemaker MJ, Wright LB, Ashworth A, Swerdlow AJ: Smoking and risk of breast cancer in the Generations Study cohort. Breast Cancer Res 2017, 19(1):118. 
33. Kispert S, McHowat J: Recent insights into cigarette smoking as a lifestyle risk factor for breast cancer. Breast Cancer (Dove Med Press) 2017, 9:127132.

34. Goldvaser H, Gal O, Rizel S, Hendler D, Neiman V, Shochat T, Sulkes A, Brenner B, Yerushalmi R: The association between smoking and breast cancer characteristics and outcome. BMC Cancer 2017, 17(1):624.

35. Therkildsen C, Ladelund S, Smith-Hansen L, Lindberg LJ, Nilbert M: Towards gene- and gender-based risk estimates in Lynch syndrome; age-specific incidences for 13 extra-colorectal cancer types. Br J Cancer 2017, 117(11):1702-1710.

36. Ryan NAJ, Glaire MA, Blake D, Cabrera-Dandy M, Evans DG, Crosbie EJ: The proportion of endometrial cancers associated with Lynch syndrome: a systematic review of the literature and meta-analysis. Genet Med 2019.

37. Gerber DE, Laccetti AL, Xuan L, Halm EA, Pruitt SL: Impact of prior cancer on eligibility for lung cancer clinical trials. J Nat/ Cancer Inst 2014, 106(11).

38. Bradley CJ, Yabroff KR, Mariotto AB, Zeruto C, Tran Q, Warren JL: Antineoplastic Treatment of Advanced-Stage Non-Small-Cell Lung Cancer: Treatment, Survival, and Spending (2000 to 2011). J Clin Oncol 2017, 35(5):529-535.

39. Brooks GA, Austin AM, Uno H, Dragnev KH, Tosteson ANA, Schrag D: Hospitalization and Survival of Medicare Patients Treated With Carboplatin Plus Paclitaxel or Pemetrexed for Metastatic, Nonsquamous, Non-Small Cell Lung Cancer. JAMA Netw Open 2018, 1(6):e183023-e183023.

40. Kim ES, Bruinooge SS, Roberts S, Ison G, Lin NU, Gore L, Uldrick TS, Lichtman SM, Roach N, Beaver JA et al: Broadening Eligibility Criteria to Make Clinical Trials More Representative: American Society of Clinical Oncology and Friends of Cancer Research Joint Research Statement. Journal of Clinical Oncology 2017, 35(33):3737-3744.

41. Rothman. KJ, Greenland. S, Lash TL: Modern Epidemiology, Third Edition: Lippincott Williams \& Wilkins; 2008.

42. Rothman KJ: Epidemiology: an introduction, 2nd edition: Oxford university press; 2012.

43. Pearce N: Effect measures in prevalence studies. Environ Health Perspect 2004, 112(10):1047-1050.

44. Pearce N: Classification of epidemiological study designs. Int J Epidemio/ 2012, 41(2):393-397.

\section{Figures}

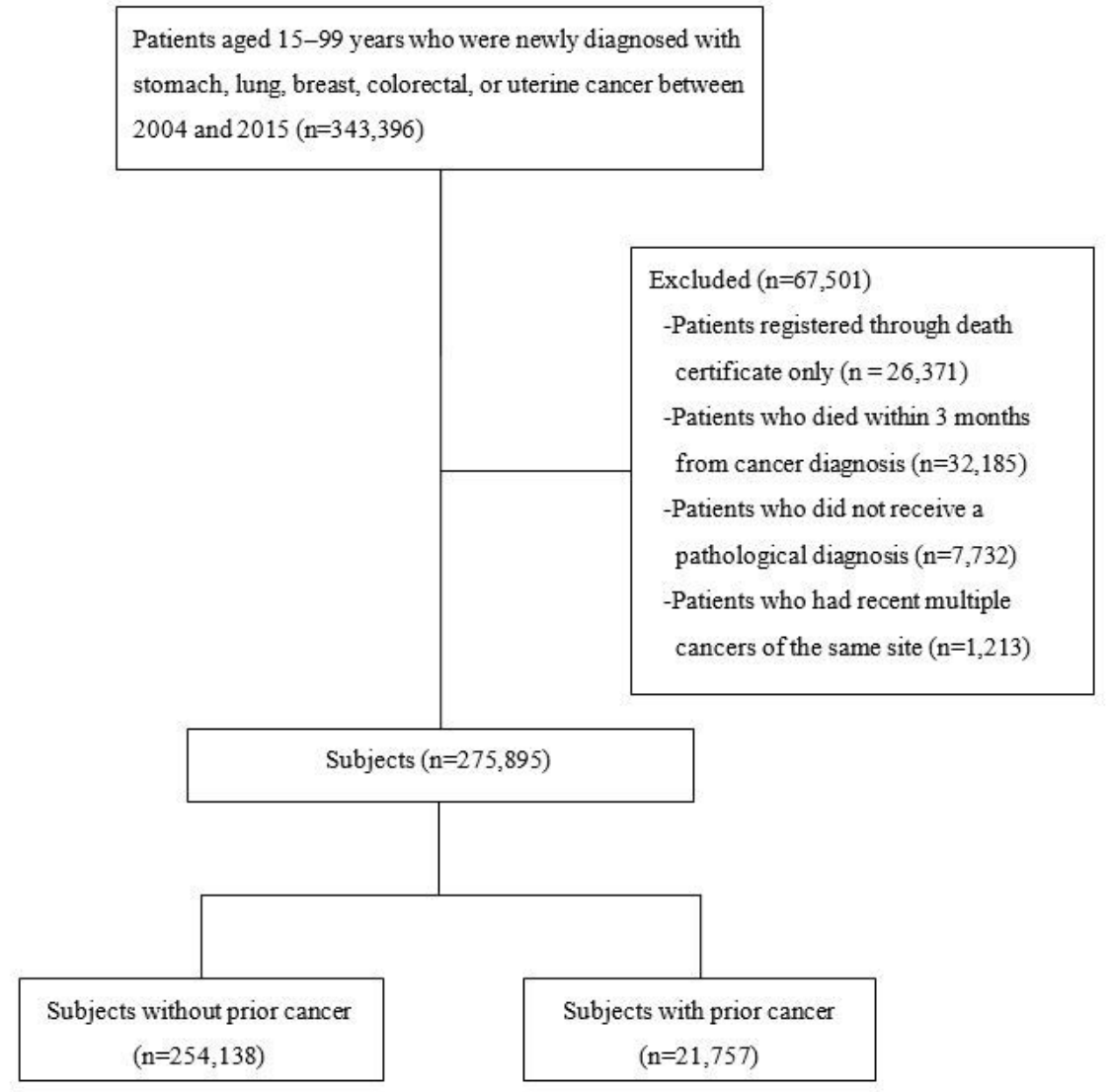

Figure 1

Flow diagram of study subject selection 


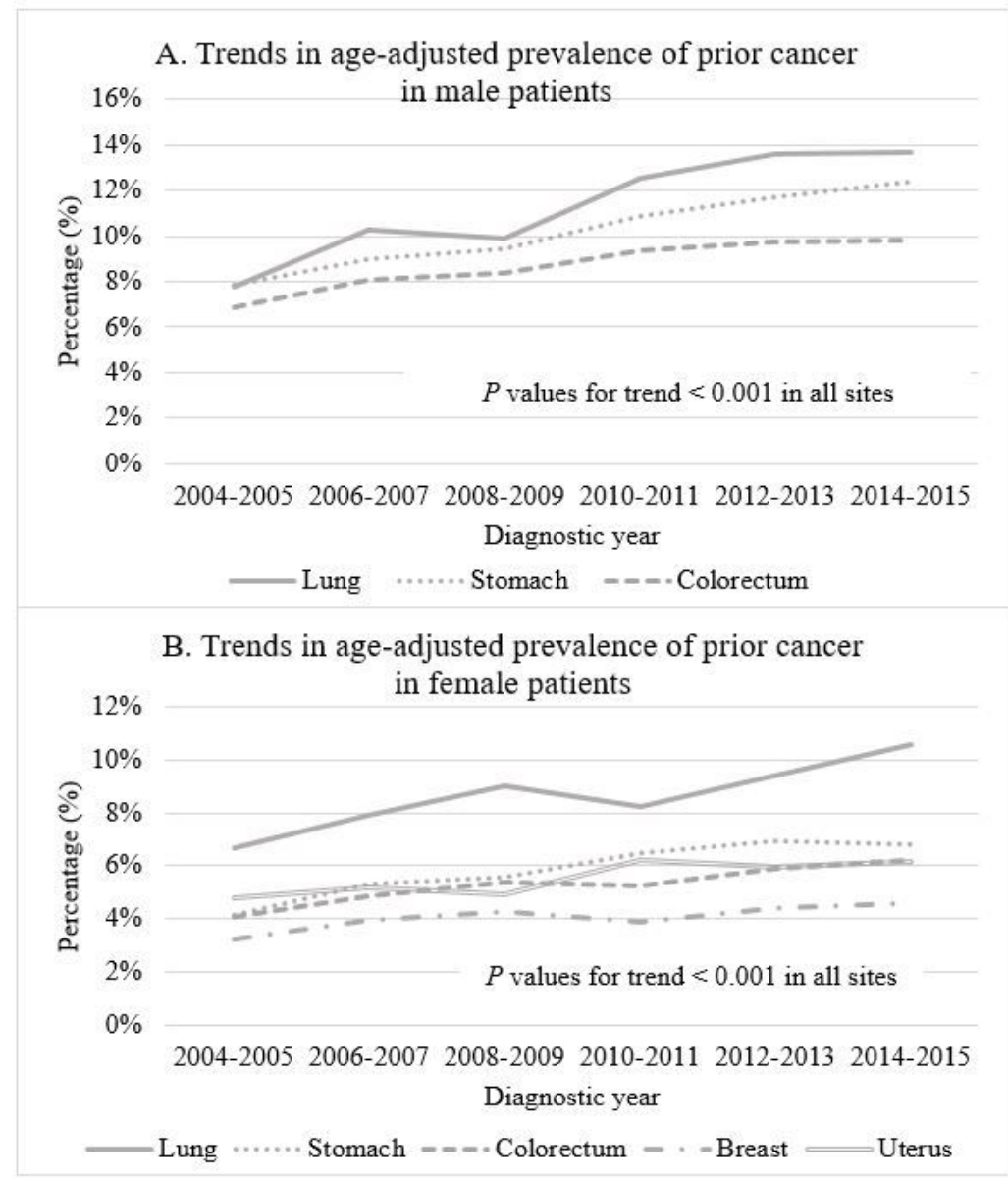

Figure 2

Trends in the age-adjusted prevalence of prior cancer between 2004 and 2015 The graphs show the age-adjusted prevalence of prior cancer in (A) male and (B) female patients according to index cancer site. P values for trend over the study period were calculated using the Cochran-Armitage test. The percentage of death certificate notification cases (DCN\%) according to each diagnostic year was $26.2 \%$ in $2004-2005,19.7 \%$ in $2006-2007,16.5 \%$ in $2008-2009$, $12.3 \%$ in $2010-2011,9.0 \%$ in $2012-2013$, and $6.0 \%$ in $2014-2015$.

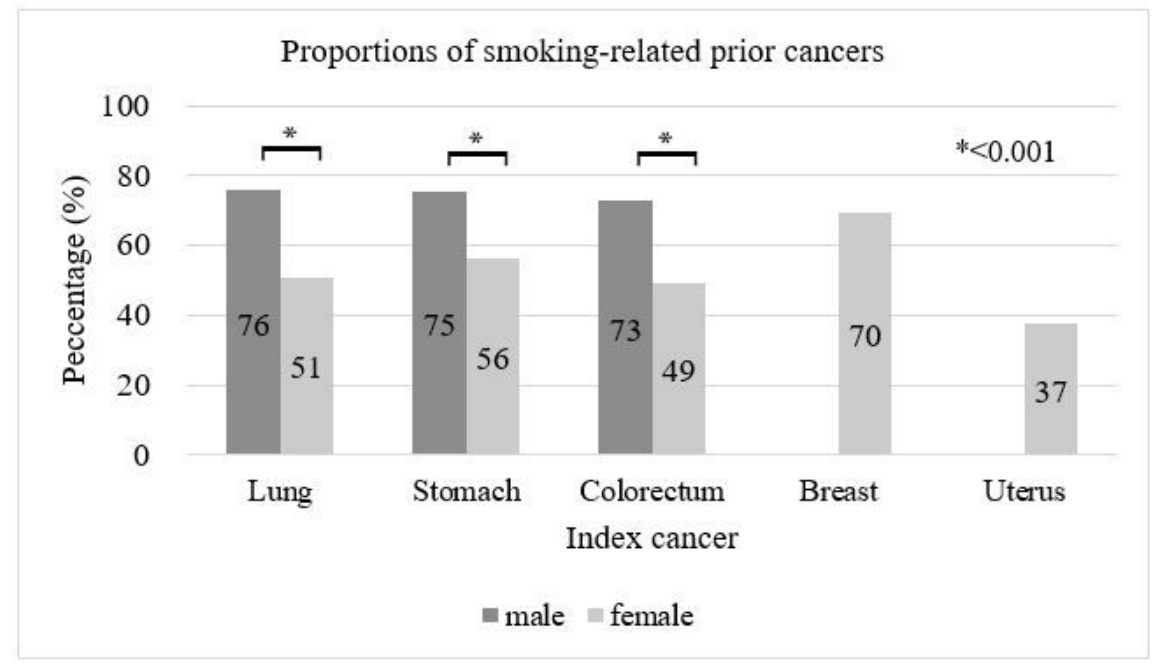

Figure 3

Proportions of smoking-related prior cancers according to index cancer site Smoking-related prior cancers included cancers of the mouth, pharynx, larynx, lung, esophagus, stomach, liver, pancreas, kidney, urinary bladder, colorectum, uterine cervix, and acute myeloid leukemia. Pearson's chi-square test was used 
to compare the proportions of smoking-related prior cancers between the sexes.

\section{Supplementary Files}

This is a list of supplementary files associated with this preprint. Click to download.

- Additionalfile.docx 